\title{
ERRATUM
}

\section{Microbial individuality in the natural environment}

\author{
M Ackermann
}

The ISME Journal (2014) 8, 492; doi:10.1038/ismej.2013.184

Correction to: The ISME Journal (2013) 7, 465-467; doi:10.1038/ismej.2012.131

Since the publication of this article, the author has identified an error contained within the following sentence (located on page 1):

However, there is a third possibility that transcends the traditional concept of nature and nurture as determinants of the phenotype: that phenotypic diversity is produced independently of genetic for example, see environmental variation.

The correct sentence should read:

However, there is a third possibility that transcends the traditional concept of nature and nurture as determinants of the phenotype: that phenotypic diversity is produced independently of genetic and environmental variation.

The Publisher would like to apologize for any inconvenience this may have caused.

\section{CORRIGENDUM}

\section{Sympatric inhibition and niche differentiation suggest alternative coevolutionary trajectories among Streptomycetes}

\author{
Linda L Kinkel, Daniel C Schlatter, Kun Xiao and Anita D Baines
}

The ISME Journal (2014) 8, 492; doi:10.1038/ismej.2013.213

Correction to: The ISME Journal (2014) 8, 249-256; doi:10.1038/ismej.2013.175; published online 24 October 2013

Since the online publication of this article, the authors have identified an error concerning Figure 2, namely that the incorrect figure was displayed.

The correct figure is shown here.

This error has now been rectified, and the corrected article appears in this issue. The html and online pdf versions have also been rectified, and now carry the correct paper.

The authors would like to apologise for any inconvenience this may have caused.

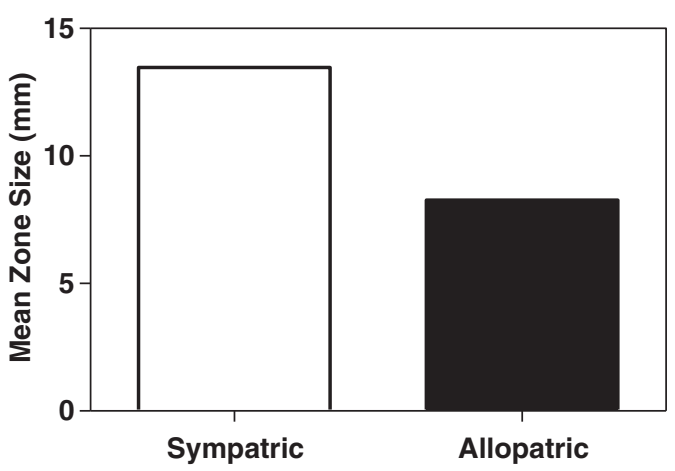

Figure 2 Intensity of antibiotic inhibition (mean zone size) among all inhibitory isolate pairs from the same (sympatric, $n=118$ interactions) and different (allopatric, $n=667$ interactions) locations. Mean zone size differed significantly among sympatric vs allopatric isolate pairs $(P<0.0001$, Welch twosample $t$-test). 